\title{
On Computation of Edge Degree-Based Banhatti Indices of a Certain Molecular Network
}

\author{
Jiang-Hua Tang, ${ }^{1}$ Muhammad Abid, ${ }^{2}$ Kashif Ali, ${ }^{2}$ Asfand Fahad $\left(D^{3},{ }^{3}\right.$ \\ Muhammad Anwar Chaudhry, ${ }^{4}$ Muhammad Imran Qureshi $\mathbb{D}^{3},{ }^{3}$ and Jia-Bao Liu $\mathbb{D}^{5}$ \\ ${ }^{1}$ Department of General Education, Anhui Xinhua University, Hefei 230088, China \\ ${ }^{2}$ Department of Mathematics, COMSATS University Islamabad, Lahore Campus, Lahore, Pakistan \\ ${ }^{3}$ Department of Mathematics, COMSATS University Islamabad, Vehari Campus, Vehari 61100, Pakistan \\ ${ }^{4}$ Department of Mathematics and Statistics, Institute of Southern Punjab, Multan, Pakistan \\ ${ }^{5}$ School of Mathematics and Physics, Anhui Jianzhu University, Hefei, China \\ Correspondence should be addressed to Muhammad Imran Qureshi; imranqureshi18@gmail.com
}

Received 19 August 2021; Accepted 16 October 2021; Published 5 November 2021

Academic Editor: Xiangfeng Yang

Copyright (c) 2021 Jiang-Hua Tang et al. This is an open access article distributed under the Creative Commons Attribution License, which permits unrestricted use, distribution, and reproduction in any medium, provided the original work is properly cited.

Chemical graph theory deals with the basic properties of a molecular graph. In graph theory, we correlate molecular descriptors to the properties of molecular structures. Here, we compute some Banhatti molecular descriptors for water-soluble dendritic unimolecular polyether micelle. Our results prove to be very significant to understand the behaviour of water-soluble dendritic unimolecular polyether micelle as a drug-delivery agent.

\section{Introduction}

Topological indices are graph invariants associated with numbers that describe the properties of the graph. In chemical graph theory, topological indices play a vital role to explore the structures of different graphs. In 1947, Harold Wiener gave the idea of topological indices [1]. After that, he published a series of papers describe the relation between wiener index and physicochemical properties of carbon-based compounds $[2,3]$ in 1947 and $[4,5]$ in 1948. The analysis of topological indices has great importance in nanotechnology and theoretical chemistry. The irregularity of graph was discussed [6] in 1997. In the last decade of the $20^{\text {th }}$ century, a large number of topological indices were introduced that were related to the Wiener index. In the second decade of the $21^{\text {st }}$ century, irregularity topological indices were computed for different chemical structures. In [7], it was shown that Randic and modified Zagreb indices are in oneto-one correspondence for all acyclic molecules which consist of no more than 100 atoms. In [8], the new notion of total irregularity was introduced, and the authors determined the graphs with maximum total irregularity. In [9-11], the total irregularity of graphs was discussed under the graph operations. In [12], the total irregularity of graphs was discussed to study QSPR. An Indian mathematician Kulli in 2016 [13] introduced some new Banhatti indices such as K Banhatti indices, modified Banhatti indices and, hyper $\mathrm{K}$ Banhatti indices. In the last decade, irregular, distance- and degree-based topological indices became hot topics for research in chemical graph theory. Many researchers computed these indices for different chemical graphs to study their biochemical properties. In [14], Zheng et al. computed some eccentricity-based topological indices and polynomials of Poly(EThylene Amido Amine) (PETAA) dendrimers. In [15], Ye et al. worked on the Zagreb connection number index of nanotubes and regular hexagonal lattice. In [16], Fahad et al. studied the topological descriptors of Poly Propyl Ether Imine (PETIM) dendrimers. In [17], Qureshi studied the Zagreb connection index of drug-related chemical structures. In [18], Zhang et al. worked on a newly defined topological index named face index for silicon carbides. In [19], Luo et al. computed lower bounds on the entire Zagreb indices 
of trees. In [20], Chu et al. studied the irregular indices for metal organic frameworks and certain 2D lattices. The Zagreb connection index is computed for silicate, hexagonal, honeycomb, and oxide networks in [21] in 2021. In [22], Rao et al. studied some degree-based topological indices of a caboxy-terminated dendritic macromolecule. In [23], the authors computed the face index for Boron triangular nanotubes and for quadrilateral sections cut from a regular hexagonal lattice. In [24], Hussain et al. computed topological indices for new classes of Benes network.

Let $G(V, E)$ be a graph where $V$ is a set of vertices and $E$ is a set of edges. A cardinality of edges associated with a vertex is called the degree of the vertex. Here, we use a special term of $e=s t$ as an edge of $G$ where the vertex $s$ and vertex $t$ are linked together by edge $e$. Let $d_{G}(e)$ denote the degree of an edge $e$ in $G$, which is defined by $d_{G}(e)=d_{G}(s)+d_{G}(t)-2$ with $e=s t$. For more details, refer the work of Kulli [25].

The first and second $K$ Banhatti indices were introduced by Kulli in [13] as

$$
\begin{aligned}
& B_{1}(G)=\sum_{e=s t \in E(G)}\left[d_{G}(s)+d_{G}(e)\right], \\
& B_{2}(G)=\sum_{e=s t \in E(G)}\left[d_{G}(s) * d_{G}(e)\right] .
\end{aligned}
$$

The first and second $K$ hyper Banhatti index of $G$ were introduced by Kulli in [26] defined as

$$
\begin{aligned}
& \operatorname{HB}_{1}(G)=\sum_{e=s t \in E(G)}\left[d_{G}(s)+d_{G}(e)\right]^{2}, \\
& \operatorname{HB}_{2}(G)=\sum_{e=s t \in E(G)}\left[d_{G}(s) * d_{G}(e)\right]^{2} .
\end{aligned}
$$

The first and second modified Banhatti indices of $G$ were introduced by Kulli in [27] as

$$
\begin{aligned}
& \mathrm{mB}_{1}(G)=\sum_{e=s t \in E(G)}\left[\frac{1}{\left(d_{G}(s)+d_{G}(e)\right)+\left(d_{G}(t)+d_{G}(e)\right)}\right], \\
& \mathrm{mB}_{2}(G)=\sum_{e=s t \in E(G)}\left[\frac{2}{\left(d_{G}(s)+d_{G}(e)\right)+\left(d_{G}(t)+d_{G}(e)\right)}\right] .
\end{aligned}
$$

The harmonic $K$-Banhatti index of a graph $G$ was introduced by Kulli in [27] as

$$
H_{b}(G)=\sum_{e=s t \in E(G)}\left[\frac{2}{\left(d_{G}(s)+d_{G}(e)\right)+\left(d_{G}(t)+d_{G}(e)\right)}\right] \text {. }
$$

Let $G$ be a graph of water-soluble dendritic unimolecular polyether micelle. It has $38\left(2^{n}\right)-4$ number of vertices and $42\left(2^{n}\right)-5$ number of edges where $n$ is the number of growth of the graph. The graph has $4\left(2^{n}\right)$ number of vertices having degree $1,22\left(2^{n}\right)-2$ vertices having degree 2 and $12\left(2^{n}\right)-2$ vertices having degree 3 . The graph has $4\left(2^{n}\right)$ number of edges having degree $(1,3), 8\left(2^{n}\right)+2$ edges having degree $(2,2), 28\left(2^{n}\right)-8$ edges having degree $(2,3)$, and $(2,3)$ number of edges having degree $(3,3)$. In Figure 1, the graph $G$ is given for $n=4$. Dendritic unimolecular micelles play an important role in drug delivery systems. Unimolecular micelles have a unique property of uniform size and high stability. Also, they have attracted increasing attention due to their high functionality in various applications.

In the next section, we will compute the Banhatti indices for the water-soluble dendritic unimolecular polyether micelle.

\section{Main Results}

Table 1 shows the partition of the edge set for the molecular graph $G$ of water-soluble dendritic unimolecular polyether micelle.

Theorem 1. Let $G$ be the molecular graph of water-soluble dendritic unimolecular polyether micelle; then, the first $K$ Banhatti index of $G$ is

$$
B_{1}(G)=432\left(2^{n}\right)-58 .
$$

Proof. By using Table 1 and the definition of the first $K$ Banhatti index, we have

$$
\begin{aligned}
B_{1}(G)= & \sum_{e=s t \in E(G)}\left[d_{G}(s)+d_{G}(e)\right] \\
= & 4\left(2^{n}\right)[(1+2)+(3+2)]+\left(8\left(2^{n}\right)+2\right)[(2+2)+(2+2)] \\
& +\left(28\left(2^{n}\right)-8\right)[(2+3)+(3+3)]+\left(2\left(2^{n}\right)+1\right)[(3+4)+(3+4)], \\
= & 32\left(2^{n}\right)+64\left(2^{n}\right)+16+308\left(2^{n}\right)-88+28\left(2^{n}\right)+14, \\
= & 432\left(2^{n}\right)-58 .
\end{aligned}
$$




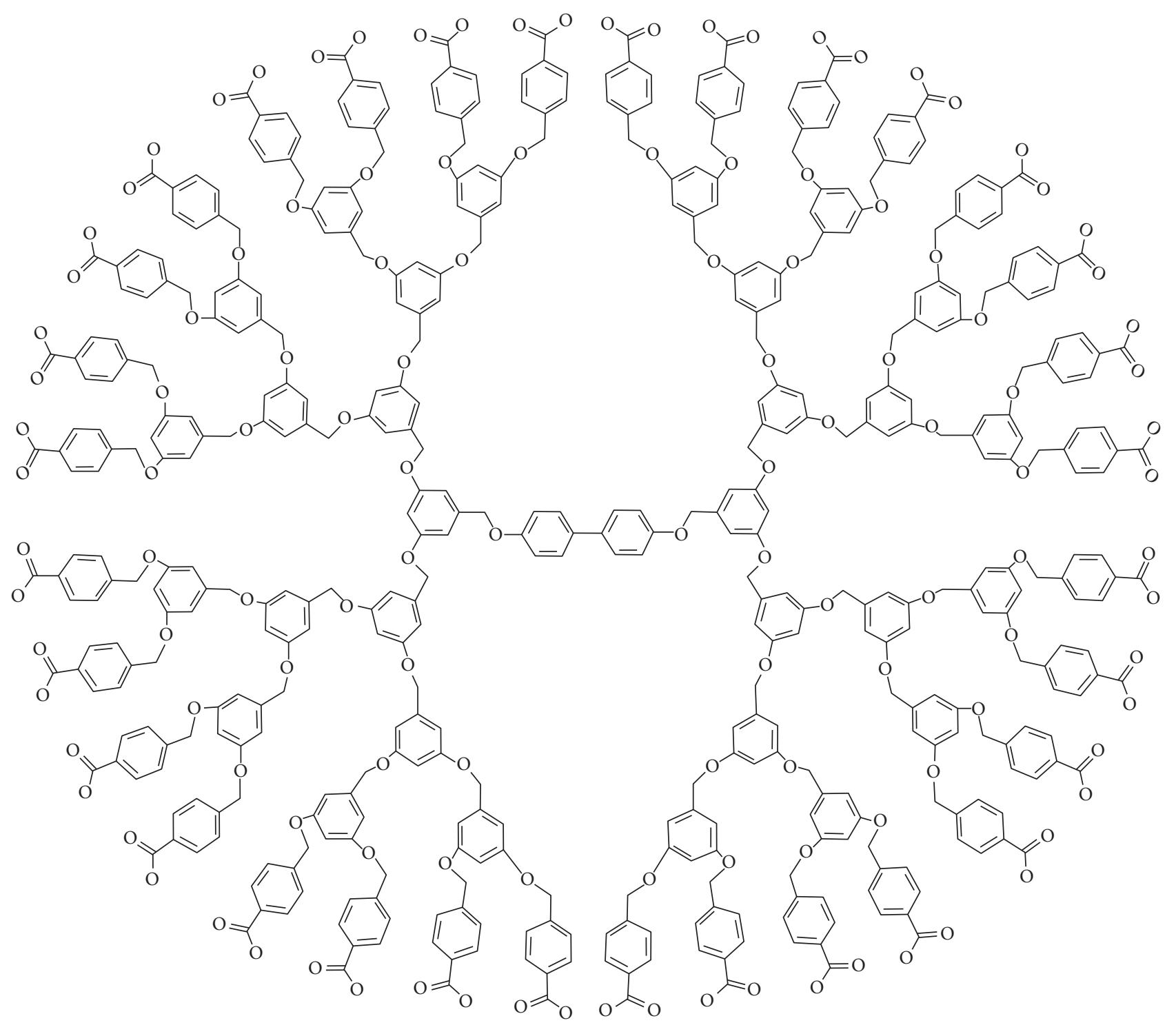

Figure 1: Graph of water-soluble unimolecular polyether micelle for growth four.

TABLE 1: Edge partition of water-soluble dendritic unimolecular polyether micelle.

\begin{tabular}{lcc}
\hline$\left(d_{G}(s), d_{G}(t)\right)$, where $s t \epsilon E(G)$ & $d_{G}(e)$ & Number of edges \\
\hline$(1,3)$ & 2 & $4\left(2^{n}\right)$ \\
$(2,2)$ & 2 & $8\left(2^{n}\right)+2$ \\
$(2,3)$ & 3 & $28\left(2^{n}\right)-8$ \\
$(3,3)$ & 4 & $2\left(2^{n}\right)+1$ \\
\hline
\end{tabular}


Theorem 2. Let $G$ be the molecular graph of water-soluble dendritic unimolecular polyether micelle; then, the second $K$ Banhatti index of $G$ is

$$
B_{2}(G)=564\left(2^{n}\right)-80 .
$$

Proof. To compute the second $K$ Banhatti index, we will use Table 1.

$$
\begin{aligned}
B_{2}(G)= & \sum_{e=s t \in E(G)}\left[d_{G}(s) * d_{G}(e)\right], \\
= & 4\left(2^{n}\right)[(1 * 2)+(3 * 2)]+\left(8\left(2^{n}\right)+2\right)[(2 * 2)+(2 * 2)] \\
& +\left(28\left(2^{n}\right)-8\right)[(2 * 3)+(3 * 3)]+\left(2\left(2^{n}\right)+1\right)[(3 * 4)+(3 * 4)], \\
= & 32\left(2^{n}\right)+64\left(2^{n}\right)+16+420\left(2^{n}\right)-120+48\left(2^{n}\right)+24, \\
= & 564\left(2^{n}\right)-80 .
\end{aligned}
$$

Theorem 3. Let $G$ be the molecular graph of water-soluble dendritic unimolecular polyether micelle; then, the first $K$ hyper Banhatti index of $G$ is

$$
\mathrm{HB}_{1}(G)=2296\left(2^{n}\right)-326 .
$$

Proof. The edge partition given in Table 1 and the definition of the first $K$ hyper Banhatti index give

$$
\begin{aligned}
\mathrm{HB}_{1}(G)= & \sum_{e=s t \in E(G)}\left[d_{G}(s)+d_{G}(e)\right]^{2}, \\
= & 4\left(2^{n}\right)\left[(1+2)^{2}+(3+2)^{2}\right]+\left(8\left(2^{n}\right)+2\right)\left[(2+2)^{2}+(2+2)^{2}\right] \\
& +\left(28\left(2^{n}\right)-8\right)\left[(2+3)^{2}+\left(3+3^{2}\right)\right]+\left(2\left(2^{n}\right)+1\right)\left[(3+4)^{2}+(3+4)^{2}\right], \\
= & 136\left(2^{n}\right)+256\left(2^{n}\right)+64+1708\left(2^{n}\right)-488+196\left(2^{n}\right)+98, \\
= & 2296\left(2^{n}\right)-326 .
\end{aligned}
$$

Theorem 4. Let $G$ be the molecular graph of water-soluble dendritic unimolecular polyether micelle; then, the second $K$ hyper Banhatti index of $G$ is

$$
\mathrm{HB}_{2}(G)=4268\left(2^{n}\right)-584 \text {. }
$$

Proof. The result follows by using the values from Table 1 and the definition of the second $K$ hyper Banhatti index.

$$
\begin{aligned}
\mathrm{HB}_{2}(G)= & \sum_{e=s t \in E(G)}\left[d_{G}(s) * d_{G}(e)\right]^{2} \\
= & 4\left(2^{n}\right)\left[(1 * 2)^{2}+(3 * 2)^{2}\right]+\left(8\left(2^{n}\right)+2\right)\left[(2 * 2)^{2}+(2 * 2)^{2}\right] \\
& +\left(28\left(2^{n}\right)-8\right)\left[(2 * 3)^{2}+(3 * 3)^{2}\right]+\left(2\left(2^{n}\right)+1\right)\left[(3 * 4)^{2}+(3 * 4)^{2}\right], \\
= & 160\left(2^{n}\right)+256\left(2^{n}\right)+64+3276\left(2^{n}\right)-936+576\left(2^{n}\right)+288 \\
= & 4268\left(2^{n}\right)-584 .
\end{aligned}
$$


TABLE 2: Banhatti indices of water-soluble dendritic unimolecular polyether micelle.

\begin{tabular}{|c|c|c|c|c|c|}
\hline Banhatti indices & $n=1$ & $n=2$ & $n=3$ & $n=4$ & $n=5$ \\
\hline$B_{1}(G)$ & 806 & 1670 & 3398 & 6854 & 13766 \\
\hline$B_{2}(G)$ & 1048 & 2176 & 4432 & 8944 & 17968 \\
\hline $\mathrm{HB}_{1}(G)$ & 4266 & 8858 & 18042 & 36410 & 73146 \\
\hline $\mathrm{HB}_{2}(G)$ & 7952 & 16488 & 33560 & 67704 & 135992 \\
\hline $\mathrm{mB}_{1}(G)$ & 7.9709 & 16.3477 & 33.1013 & 66.6085 & 133.6229 \\
\hline $\mathrm{mB}_{2}(G)$ & 6.6584 & 13.5584 & 27.3584 & 54.9584 & 110.1584 \\
\hline$H_{b}(G)$ & 15.9416 & 32.6948 & 66.2012 & 133.214 & 267.2396 \\
\hline
\end{tabular}

Theorem 5. Let $\mathrm{G}$ be the molecular graph of water-soluble dendritic unimolecular polyether micelle; then, the first modified Banhatti index of $G$ is

$$
\mathrm{mB}_{1}(G)=4.1884\left(2^{n}\right)-0.4059 \text {. }
$$

$$
\begin{aligned}
\mathrm{mB}_{1}(G)= & \sum_{e=s t \in E(G)}\left[\frac{1}{\left(d_{G}(s)+d_{G}(e)\right)+\left(d_{G}(t)+d_{G}(e)\right)}\right], \\
= & 4\left(2^{n}\right)\left[\frac{1}{(1+2)+(3+2)}\right]+\left(8\left(2^{n}\right)+2\right)\left[\frac{1}{(2+2)+(2+2)}\right]+ \\
& \left(28\left(2^{n}\right)-8\right)\left[\frac{1}{(2+3)+(3+3)}\right]+\left(2\left(2^{n}\right)+1\right)\left[\frac{1}{(3+4)+(3+4)}\right], \\
= & \frac{2^{n}}{2}+2^{n}+\frac{1}{4}+\frac{28\left(2^{n}\right)}{11}-\frac{8}{11}+\frac{2^{n}}{7}+\frac{1}{14}, \\
= & 4.1884\left(2^{n}\right)-0.4059 .
\end{aligned}
$$

Theorem 6. Let $G$ be the molecular graph of water-soluble dendritic unimolecular polyether micelle; then, the second modified Banhatti index of $G$ is

$$
\mathrm{mB}_{2}(G)=3.45\left(2^{n}\right)-0.2416 .
$$

$$
\begin{aligned}
\mathrm{mB}_{2}(G)= & \sum_{e=s t \in E(G)}\left[\frac{2}{\left(d_{G}(s)+d_{G}(e)\right)+\left(d_{G}(t)+d_{G}(e)\right)}\right], \\
= & 4\left(2^{n}\right)\left[\frac{1}{(1 \times 2)+(3 \times 2)}\right]+\left(8\left(2^{n}\right)+2\right)\left[\frac{2}{(2 \times 2)+(2 \times 2)}\right]+ \\
& \left(28\left(2^{n}\right)-8\right)\left[\frac{2}{(2 \times 3)+(3 \times 3)}\right]+\left(2\left(2^{n}\right)+1\right)\left[\frac{2}{(3 \times 4)+(3 \times 4)}\right], \\
= & \frac{2^{n}}{2}+2^{n}+\frac{1}{4}+\frac{28\left(2^{n}\right)}{15}-\frac{8}{15}+\frac{2^{n}}{12}+\frac{1}{24}, \\
= & 3.45\left(2^{n}\right)-0.2416 .
\end{aligned}
$$




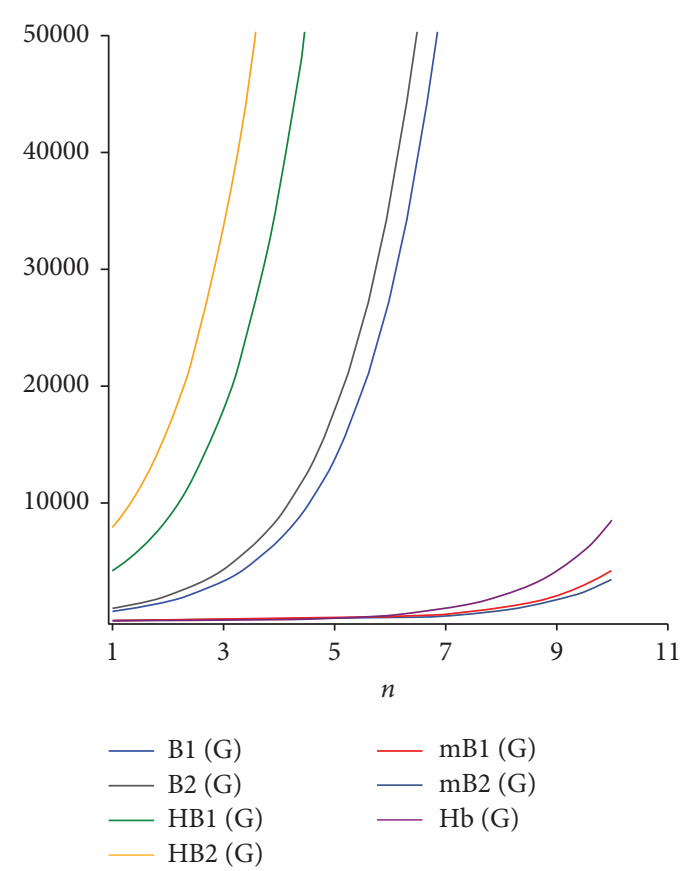

Figure 2: Comparison graph of Banhatti indices of water-soluble unimolecular polyether micelle for growth four.

Theorem 7. Let $G$ be the molecular graph of water-soluble dendritic unimolecular polyether micelle; then, the harmonic Banhatti index of $G$ is

$$
H_{b}(G)=8.3766\left(2^{n}\right)-0.8116 .
$$

$$
\begin{aligned}
H_{b}(G)= & \sum_{e=s t \in E(G)}\left[\frac{2}{\left(d_{G}(s)+d_{G}(e)\right)+\left(d_{G}(t)+d_{G}(e)\right)}\right], \\
= & 4\left(2^{n}\right)\left[\frac{2}{(1+2)+(3+2)}\right]+\left(8\left(2^{n}\right)+2\right)\left[\frac{2}{(2+2)+(2+2)}\right]+ \\
& \left(28\left(2^{n}\right)-8\right)\left[\frac{2}{(2+3)+(3+3)}\right]+\left(2\left(2^{n}\right)+1\right)\left[\frac{2}{(3+4)+(3+4)}\right], \\
= & 2^{n}+2\left(2^{n}\right)+\frac{1}{2}+\frac{56\left(2^{n}\right)}{11}-\frac{16}{11}+\frac{2\left(2^{n}\right)}{7}+\frac{2}{14} \\
= & 8.3766\left(2^{n}\right)-0.8116 .
\end{aligned}
$$




\section{Graphical Analysis and Conclusions}

This section actually provides the summary of this article. Table 2 gives the comparison for the said topological indices of the graph. We can see that $\mathrm{mB}_{2}(G)$ gives the least values for different growths of the graph whereas $\mathrm{HB}_{2}(G)$ gives largest values. In Table 2, we can check the values for some test values of parameter $n$. Also, the graphical comparison is presented in Figure 2.

\section{Data Availability}

No data were used to support for this research.

\section{Conflicts of Interest}

The authors declare no conflicts of interest.

\section{Authors' Contributions}

All authors contributed equally to the writing of this article.

\section{Acknowledgments}

This work was supported in part by the General Project of Anhui 2021 University excellent talent support plan under Grant gxyq2021235.

\section{References}

[1] H. Wiener, "Structural determination of Paraffin boiling points," Journal of the American Chemical Society, vol. 69, pp. 17-20, 1947.

[2] H. Wiener, "Correlation of heats of isomerization, and differences in heats of vaporization of isomers, among the paraffin hydrocarbons," Journal of the American Chemical Society, vol. 69, no. 11, pp. 2636-2638, 1947.

[3] H. Wiener, "Influence of interatomic forces on paraffin properties," The Journal of Chemical Physics, vol. 15, no. 10, p. 766, 1947.

[4] H. Wiener, "The prediction of thermal pressure," Journal of Physical Chemistry, vol. 52, no. 6, pp. 1082-1089, 1948.

[5] H. Wiener, "Vapour pressure-temperature relationships among the branched paraffin hydrocarbons," Journal of Physical Chemistry, vol. 52, pp. 425-430, 1948.

[6] M. Albertson, "The irregularity of a graph," Ars Combinatoria, vol. 46, pp. 219-225, 1997.

[7] D. Vukicevic and A. Groavac, "Valence connectivities verses Randic, Zagreb and modified Zagreb index: a linear algorithm to check discriminative properties of indices in acyclic molecular graphs," Croatica Chemica Acta, vol. 77, no. 3, pp. 501-508, 2004.

[8] H. Abdo, S. Brandit, and D. Dimitrov, "The total irregularity of a graph," Discrete Mathematics \& Theoretical Computer Science, vol. 16, pp. 201-206, 2014.

[9] H. Abdo and D. Dimitrov, "The total irregularity of graphs under graph operations," Miskolc Mathematical Notes, vol. 15, pp. 3-17, 2014.

[10] H. Abdo and D. Dimitrov, "The irregularity of graphs under graph operations," Discussiones Mathematicae Graph Theory, vol. 34, no. 2, pp. 263-278, 2014.

[11] I. Gutman, "Topological indices and irregularity measures," Jewish Bulletin, vol. 8, pp. 469-475, 2018.
[12] T. Reti, R. Sharfdini, A. Dregelyi-kiss, and H. Hagobin, "Graph Irregularity indices used as molecular descriptors on QSPR studies," MATCH Communications in Mathematical and in Computer Chemistry, vol. 79, no. 2, pp. 509-524, 2018.

[13] V. R. Kulli, "On K banhatti indices of graphs," Journal of Computer and Mathematical Sciences, vol. 7, pp. 213-218, 2016.

[14] J. Zheng, Z. Iqbal, A. Fahad et al., "Some eccentricity-based topological indices and Polynomials of poly(EThyleneAmidoAmine) (PETAA) dendrimers," Processes, vol. 7, no. 7, p. 433, 2019.

[15] A. Ye, M. I. Qureshi, A. Fahad et al., "Zagreb Connection number index of Nanotubes and regular hexagonal lattice," Open Chemistry, vol. 17, no. 1, pp. 75-80, 2019.

[16] A. Fahad, M. I. Qureshi, S. Noureen, Z. Iqbal, A. Zafar, and M. Ishaq, "Topological descriptors of poly propyl ether imine (PETIM) dendrimers," Biointerface Research in Applied Chemistry, vol. 11, pp. 10968-10978, 2021.

[17] M. I. Qureshi, A. Fahad, M. K. Jamil, and S. Ahmad, "Zagreb connection index of drugs related chemical structures," Biointerface Research in Applied Chemistry, vol. 11, pp. 11920-11930, 2021.

[18] X. Zhang, A. Raza, A. Fahad, M. K. Jameel, M. A. Chaudhry, and Z. Iqbal, "On face index of Silicon carbides," Discrete Dynamics in Nature and Society, vol. 8, 2020.

[19] L. Luo, N. Dehgardi, and A. Fahad, "Lower bounds on the entire zagreb indices of trees," Discrete Dynamics in Nature and Society, vol. 8, 2020.

[20] Y.-M. Chu, M. Abid, M. I. Qureshi, A. Fahad, and A. Aslam, "Irregular topological indices of certain metal organic frameworks," Main Group Metal Chemistry, vol. 44, no. 1, pp. 73-81, 2021.

[21] A. Fahad, A. Aslam, M. I. Qureshi, M. K. Jamil, and A. Jaleel, "Zagreb connection indices of some classes of networks," Biointerface Research in Applied Chemistry, vol. 11, no. 3, pp. 10074-10081, 2021.

[22] Y. Rao, A. Kanwal, R. Abbas, S. Noureen, A. Fahad, and M. I. Qureshi, "Some degree-based topological indices of caboxy-terminated dendritic macromolecule," Main Group Metal Chemistry, vol. 44, no. 1, pp. 165-172, 2021.

[23] S. Ding, M. I. Qureshi, S. F. Shah, A. Fahad, M. K. Jamil, and J. B. Liu, "Face index of nanotubes and regular hexagonal lattices," International Journal of Quantum Chemistry, vol. 1-11, 2021.

[24] A. Hussain, M. Numan, N. Naz, S. I. butt, A. Aslam, and A. Fahad, "On topological indices for new classes of Benes network," Jurnal Matematika, vol. 7, 2021.

[25] V. R. Kulli, College Graph Theory, Vishwa International Publications, Gulbarga, India, 2012.

[26] V. R. Kulli, "On $K$ hyper Banhatti indices and coindices of graphs," International Research Journal of Pure Algrbra, vol. 6, no. 5, pp. 300-304, 2016.

[27] V. R. Kulli, "New K-banhatti topological indices," International Journal of Fuzzy Mathematical Archive, vol. 12, no. 1, pp. 29-37, 2017. 